\title{
Carbonate clumped isotope thermometry of deep-sea corals and implications for vital effects
}

\author{
Nivedita Thiagarajan*, Jess Adkins, John Eiler \\ California Institute of Technology, Division of Geological and Planetary Sciences, 1200 E California Blvd., Pasadena, CA 91125, USA
}

Received 1 March 2010; accepted in revised form 4 April 2011; available online 17 May 2011

\begin{abstract}
Here we calibrate the carbonate clumped isotope thermometer in modern deep-sea corals. We examined 11 specimens of three species of deep-sea corals and one species of a surface coral spanning a total range in growth temperature of $2-25{ }^{\circ} \mathrm{C}$. External standard errors for individual measurements ranged from $0.005 \%$ to $0.011 \%$ (average: $0.0074 \%$ ) which corresponds to $\sim 1-2{ }^{\circ} \mathrm{C}$. External standard errors for replicate measurements of $\Delta_{47}$ in corals ranged from $0.002 \%$ to $0.014 \%$ o (average: $0.0072 \%$ ) which corresponds to $0.4-2.8^{\circ} \mathrm{C}$. We find that skeletal carbonate from deep-sea corals shows the same relationship of $\Delta_{47}$ (the measure of ${ }^{13} \mathrm{C}-{ }^{18} \mathrm{O}$ ordering) to temperature as does inorganic calcite. In contrast, the $\delta^{13} \mathrm{C}$ and $\delta^{18} \mathrm{O}$ values of these carbonates (measured simultaneously with $\Delta_{47}$ for every sample) differ markedly from equilibrium with seawater; i.e., these samples exhibit pronounced 'vital effects' in their bulk isotopic compositions. We explore several reasons why the clumped isotope compositions of deep-sea coral skeletons exhibit no evidence of a vital effect despite having large conventional isotopic vital effects.
\end{abstract}

(c) 2011 Elsevier Ltd. All rights reserved.

\section{INTRODUCTION}

Oxygen isotope measurements of biogenic marine carbonates are a long established and important tool for determining past ocean temperatures (Urey, 1947; McCrea, 1950; Epstein et al., 1953). In the decades following its initial development, the $\delta^{18} \mathrm{O}$ thermometer was applied to planktonic foraminifera to reconstruct ocean temperature shifts on glacial/interglacial time scales (Emiliani, 1955). However it was later recognized that the planktonic record reconstructed from foraminifera $\delta^{18} \mathrm{O}$ reflects a combination of the temperature from which the carbonate grew, and global changes in ice volume (Shackleton, 1967).

Deconvolving these two effects on the marine-carbonate oxygen isotope record remains a central problem in paleoclimatology. Chappell and Shackleton (1986) addressed this problem by examining dated coral terraces and benthic $\delta^{18} \mathrm{O}$ records. Previously, the benthic $\delta^{18} \mathrm{O}$ records had been

\footnotetext{
* Corresponding author.

E-mail address: nivedita@caltech.edu (N. Thiagarajan).
}

interpreted assuming a constant temperature in the abyssal ocean. However, the resulting ice volume estimates derived from benthic $\delta^{18} \mathrm{O}$ records could not be reconciled with ice volume records derived from the altitudes of dated coral terraces. Chappell and Shackleton (1986) made a detailed comparison of a coral terrace record in the Huon Peninsula with a benthic $\delta^{18} \mathrm{O}$ record from the Pacific Ocean and concluded that during the last glacial cycle, abyssal temperatures changed only during the transition from Marine Isotope Stage (MIS) 5e to 5d, and during the last glacial termination.

Subsequent efforts have reconstructed the $\delta^{18} \mathrm{O}$ of the water of the deep ocean during the Last Glacial Maximum based on isotopic analyses of marine pore fluids (Schrag and DePaolo, 1993). Cutler et al. (2003) reconstructed a sea level curve based on fossilized surface corals from the Huon Peninsula and Barbados and combined this new sea level curve with the $\delta^{18} \mathrm{O}$ of the water of the deep ocean reconstruction determined from pore fluids (Adkins et al., 2002a). This work established that deep-sea temperatures have warmed by $4^{\circ} \mathrm{C}$ in the Atlantic and $2^{\circ} \mathrm{C}$ in the Pacific 
since the Last Glacial Maximum. In all of these studies, independent estimates of the change in sea level or of the $\delta^{18} \mathrm{O}$ of the water of the deep ocean were necessary to extract deep ocean temperatures from benthic $\delta^{18} \mathrm{O}$ data.

Carbonate clumped isotope thermometry is a new temperature proxy based on the ordering of ${ }^{13} \mathrm{C}$ and ${ }^{18} \mathrm{O}$ atoms into bonds with each other in the same carbonate molecule. The proportion of ${ }^{13} \mathrm{C}$ and ${ }^{18} \mathrm{O}$ atoms that form bonds with each other in a carbonate mineral has an inverse relationship with growth temperature. This isotopic 'clumping' phenomenon exists due to a thermodynamically controlled homogeneous isotope exchange equilibrium in the carbonate mineral (or, perhaps, in the dissolved carbonate-ion population from which the mineral grows). This exchange reaction is independent of the $\delta^{18} \mathrm{O}$ of water and $\delta^{13} \mathrm{C}$ of DIC (dissolved inorganic carbon) from which the carbonate grew; therefore it can be applied to settings where these quantities are not known (Eiler et al., 2003; Eiler and Schauble, 2004; Ghosh et al., 2006).

Here we calibrate carbonate clumped isotope thermometry in modern deep-sea corals. Deep-sea corals are a relatively new archive in paleoceanography. Their banded skeletons can be used to generate $\sim 100$ year high-resolution records without bioturbation. They also have a high concentration of uranium, allowing for accurate independent calendar ages using U-Th systematics. A thermometer in deep-sea corals could address the phasing of the offset between Northern and Southern Hemisphere in rapid climate events. The Greenland and Antarctic ice cores both show that temperature and $\mathrm{CO}_{2}$ are tightly coupled over the last several glacial interglacial events. However, the synchronization of the ice cores from the two regions using atmospheric methane concentration trapped in the ice layers revealed that Antarctica warms several thousand years before the abrupt warmings in the Northern Hemisphere (Blunier and Brook, 2001). The deep ocean is a massive heat and carbon reservoir with an appropriate time constant that could be used to explain the several 1000 years offset between the hemispheres. A temperature record of the deep ocean that spans the time period of these rapid climate events would help explain the role of the deep ocean in rapid climate change events.

Deep-sea corals are also an important resource to study vital effects because they grow without photosymbionts and grow in a relatively homogeneous environment with minimal variations in both temperature and the composition of co-existing water. Therefore, offsets from equilibrium that we observe in any chemical proxies can be attributed to biological processes associated with calcification. Previous work in surface and deep-sea corals has found evidence of isotopic disequilibrium in $\delta^{13} \mathrm{C}$ and $\delta^{18} \mathrm{O}$ (Weber and Woodhead, 1970; Weber, 1973; Emiliani et al., 1978; McConnaughey, 1989; Adkins et al., 2003). McConnaughey attributes these offsets in surface corals to kinetic and metabolic effects. However light-induced metabolic effects cannot be invoked to explain offsets in deep-sea corals because they do not have any photosymbionts. Radiocarbon dating of modern corals and their surrounding dissolved inorganic carbon (DIC) also indicate that the skeletal material of deep-sea coral is drawn almost entirely from the ambient inorganic carbon pool and not from respired
$\mathrm{CO}_{2}$ (Adkins et al., 2002b). Due to the correlation between growth banding and stable isotopes within individual corals, Adkins et al. (2003) proposed that vital effects in deep-sea corals involve a thermodynamic response to a biologically induced $\mathrm{pH}$ gradient in the calcifying region. Watson (2004) proposed a surface entrapment model in which growth rate, diffusivity, and the surface layer thickness all control crystal composition. In this model, the trace element or isotope composition of the crystal is determined by the concentration of that element in the near surface region and the outcome of the competition between crystal growth and ion migration in the near surface region.

More recently, Ghosh et al. (2006) found evidence of an anomalous enrichment in $\Delta_{47}$ values in winter growth bands in a Porites sample from the Red Sea, suggesting that surface corals may have a vital effect in this parameter. Here we look at a variety of deep-sea corals grown from different locations, and analyze their $\Delta_{47}$ values to develop a modern calibration for carbonate clumped isotope thermometry and to investigate the mechanisms of vital effects.

\section{METHODS}

Samples examined in this study were obtained from the Smithsonian collection (National Museum of Natural History). We focused on Desmophyllum sp., Caryophyllia sp., and Ennalopsammia sp. collected from a variety of locations and depths. One Porites sp. coral from the Red Sea was also analyzed. Isotopic measurements were made on pieces from the septal region of the coral that were cut using a dremel tool. For each clumped isotope measurement, $8-15 \mathrm{mg}$ from each coral was analyzed. The outsides of the coral were scraped with a dremel tool to remove any organic crusts. The sample was then digested in $103 \%$ anhydrous phosphoric acid at $25^{\circ} \mathrm{C}$ overnight. The product $\mathrm{CO}_{2}$ was extracted and purified using methods described previously (Ghosh et al., 2006).

Evolved $\mathrm{CO}_{2}$ was analyzed in a dual inlet Finnigan MAT-253 mass spectrometer with the simultaneous collection of ion beams corresponding to masses $44-49$ to obtain $\Delta_{47}, \Delta_{48}, \Delta_{49}, \delta^{13} \mathrm{C}$ and $\delta^{18} \mathrm{O}$ values. The mass 47 beam is composed of ${ }^{17} \mathrm{O}^{13} \mathrm{C}^{17} \mathrm{O},{ }^{17} \mathrm{O}^{12} \mathrm{C}^{18} \mathrm{O}$ and predominantly ${ }^{18} \mathrm{O}^{13} \mathrm{C}^{16} \mathrm{O}$ and we define $\mathrm{R}^{47}$ as the abundance of mass 47 isotopologues divided by the mass 44 isotopologue. $\left(\mathrm{R}^{47}=\right.$ $\left.\left[{ }^{17} \mathrm{O}^{13} \mathrm{C}^{17} \mathrm{O}+{ }^{17} \mathrm{O}^{12} \mathrm{C}^{18} \mathrm{O}+{ }^{18} \mathrm{O}^{13} \mathrm{C}^{16} \mathrm{O}\right] /\left[{ }^{16} \mathrm{O}^{12} \mathrm{C}^{16} \mathrm{O}\right]\right) \Delta_{47}$ is reported relative to a stochastic distribution of isotopologues for the same bulk isotopic composition. $\left(\Delta_{47}=\right.$ $\left(\left(\left(\mathrm{R}_{\text {measured }}^{47} / \mathrm{R}_{\text {stochastic }}^{47}\right)-1\right)-\left(\left(\mathrm{R}_{\text {measured }}^{46} / \mathrm{R}_{\text {stochastic }}^{46}\right)-1\right)\right.$ $\left.\left.-\left(\left(\mathrm{R}_{\text {measured }}^{45} / \mathrm{R}_{\text {stochastic }}^{45}\right)-1\right)\right) \times 1000\right)$. Masses 48 and 49 were monitored to detect any hydrocarbon contamination. Measurements of each gas consisted of 8-26 acquisitions, each of which involved 10 cycles of sample-standard comparison with an ion integration time of 20 s per cycle. Internal standard errors of this population of acquisition to acquisition for $\Delta_{47}$ ranged from $0.005 \%$ to $0.01 \%,\left(1-2{ }^{\circ} \mathrm{C}\right)$ while external standard error ranged from $0.002 \%$ to $0.014 \%$ $\left(0.4-2.7^{\circ} \mathrm{C}\right)$. The internal standard error for $\delta^{13} \mathrm{C}$ ranged from 0.5 to $1 \mathrm{ppm}$ and the internal standard error for $\delta^{13} \mathrm{C}$ ranged from 1 to $3 \mathrm{ppm}$. 
Table 1

Stable isotopic composition of corals grown at known temperatures and $\delta^{18} \mathrm{O}_{\mathrm{w}}$.

\begin{tabular}{|c|c|c|c|c|c|c|c|}
\hline Name & Genus & $\delta^{13} \mathrm{C}$ & $\begin{array}{l}\delta^{18} \mathrm{O} \text { mineral } \\
(\mathrm{PDB})\end{array}$ & $\begin{array}{l}\text { Growth } \\
\text { temperature }\left({ }^{\circ} \mathrm{C}\right)\end{array}$ & $\Delta_{47}$ & Error in $\Delta_{47}$ & $\delta^{18} \mathrm{O}_{\mathrm{w}}$ \\
\hline 47413 & Desmophyllum & -5.009 & 0.723 & 7.9 & 0.733 & 0.007 & -0.439 \\
\hline 47413 & Desmophyllum & -6.274 & 0.343 & 7.9 & 0.736 & 0.006 & -0.439 \\
\hline 47413 & Desmophyllum & -4.877 & 0.686 & 7.9 & 0.732 & 0.009 & -0.439 \\
\hline 47413 & Desmophyllum & -4.720 & 0.764 & 7.9 & 0.736 & 0.008 & -0.439 \\
\hline 47413 & Desmophyllum & -6.285 & -0.006 & 7.9 & 0.722 & 0.005 & -0.439 \\
\hline 47413 & Desmophyllum & -4.544 & 0.833 & 7.9 & 0.726 & 0.007 & -0.439 \\
\hline 47413 & Desmophyllum & -6.286 & 0.032 & 7.9 & 0.697 & 0.006 & -0.439 \\
\hline 80404 & Desmophyllum & -1.230 & 1.535 & 13.1 & 0.707 & 0.009 & 0.25 \\
\hline 80404 & Desmophyllum & -1.826 & 1.764 & 13.1 & 0.695 & 0.008 & 0.25 \\
\hline 80404 & Desmophyllum & -1.185 & 1.611 & 13.1 & 0.717 & 0.010 & 0.25 \\
\hline 47407 & Desmophyllum & -5.640 & 0.768 & 4.2 & 0.749 & 0.006 & -0.047 \\
\hline 48738 & Desmophyllum & -1.478 & 2.987 & 9.8 & 0.762 & 0.010 & 0.624 \\
\hline 48738 & Desmophyllum & -1.567 & 2.968 & 9.8 & 0.715 & 0.005 & 0.624 \\
\hline 48738 & Desmophyllum & -4.897 & 1.537 & 9.8 & 0.727 & 0.008 & 0.624 \\
\hline 47409 & Desmophyllum & -3.640 & 1.171 & 2.3 & 0.772 & 0.008 & -0.088 \\
\hline 62308 & Desmophyllum & -4.725 & 1.147 & 3.7 & 0.744 & 0.010 & 0.5 \\
\hline 77019 & Ennalopsammia & -0.212 & 3.670 & 14.3 & 0.675 & 0.004 & 0.95 \\
\hline 47531 & Ennalopsammia & -1.603 & 0.982 & 7.5 & 0.738 & 0.009 & -0.14 \\
\hline 49020 & Caryophyllia & 0.708 & 1.548 & 17.4 & 0.688 & 0.011 & 0.907 \\
\hline 45923 & Caryophyllia & 0.289 & 3.139 & 4.6 & 0.744 & 0.008 & 0.68 \\
\hline 1010252 & Caryophyllia & -0.115 & 2.818 & 6.1 & 0.744 & 0.008 & 0.222 \\
\hline BRI-1 & Porites & -1.092 & -3.720 & 25.2 & 0.650 & 0.006 & 1.91 \\
\hline BRI-2 & Porites & -1.183 & -3.670 & 25.2 & 0.639 & 0.006 & 1.91 \\
\hline BRI-3 & Porites & -1.186 & -3.659 & 25.2 & 0.648 & 0.005 & 1.91 \\
\hline BRI-4 & Porites & -1.195 & -3.664 & 25.2 & 0.615 & 0.007 & 1.91 \\
\hline
\end{tabular}

\section{RESULTS}

Table 1 summarizes results of isotopic analyses of all coral samples investigated in this study. A $0.16 \%$ range in $\Delta_{47}$ was observed among coral samples having an estimated range in growth temperature of $2-25^{\circ} \mathrm{C}$ (Table 1; Fig. 1). Two corals, 47413 and 47407 were also previously analyzed in Ghosh et al. (2006) and we have reanalyzed them here. In Ghosh et al. (2006), growth temperatures were determined using a CTD profile however we have used the LEVITUS database to determine mean annual temperature, slightly changing the growth temperature of the coral. This does not alter any of our conclusions. Table 1 also reports the $\delta^{18} \mathrm{O}_{\mathrm{PDB}}$ values of corals analyzed in this study, along with growth temperatures, and the $\delta^{18} \mathrm{O}$ values of the water from which the corals grew. The $\delta^{18} \mathrm{O}$ of the water from which the coral grew was reconstructed through a combination of the LEVITUS salinity database (http://www.ingrid. 1deo.columbia.edu/SOURCES/.LEVITUS94/.ANNUAL/. sal/) and the NASA $\delta^{18} \mathrm{O}$ of seawater database (http:// www.data.giss.nasa.gov/cgi-bin/o18data/geto18.cgi). The LEVITUS database is more finely gridded for salinity than the NASA database. So we determined the relationship between $\delta^{18} \mathrm{O}$ of the seawater and salinity near the sample

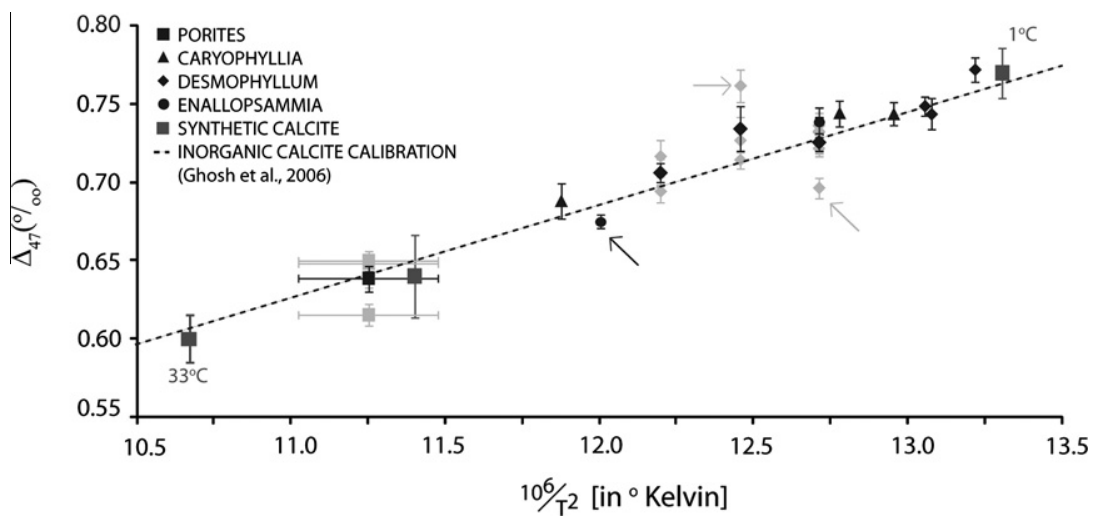

Fig. 1. Clumped isotope calibration of deep sea corals and Porites, a surface coral. The dashed line is the inorganic calibration line as determined by measuring $\mathrm{CO}_{2}$ produced from synthetic carbonates grown in the laboratory at known and controlled temperatures (Ghosh et al., 2006). The averages of replicates of the same coral (individual measurements of those corals are shown with the faded symbols) are shown with external standard errors. The measurements with arrows pointing towards them are outliers discussed in the text. 
site and used the salinity as determined by LEVITUS to calculate the $\delta^{18} \mathrm{O}$ of the seawater from the $\delta^{18} \mathrm{O}$ of the seawater vs. salinity relationship. The total error on the calculated $\delta^{18} \mathrm{O}_{\mathrm{sw}}$ ranged from $0.1 \%$ to $0.2 \%$.

Fig. 1 plots the $\Delta_{47}$ values of deep-sea corals vs. their nominal growth temperatures. The Porites surface coral BRI-1 has significant error bars in the temperature axis, unlike the deep-sea coral samples (where growth temperatures do not vary significantly seasonally), because it was collected in the Red Sea and sea surface temperatures range from 22 to $28{ }^{\circ} \mathrm{C}$ through the year (Ghosh et al., 2006). Ghosh et al. (2006) found vital effects in the winter band of BIR-1. Our analyses are of one annual band that was crushed and homogenized, and we do not observe any offsets from equilibrium. One possible explanation for this inconsistency could be that winter bands do not contribute a significant portion of the annual cycle.

The relationship of $\Delta_{47}$ to temperature is similar to that of inorganic precipitates. In a plot of $\Delta_{47}$ vs. $1 / T^{2}$ the two species of solitary corals, Desmophyllum (slope: $0.0495 \pm$ 0.012; intercept: $0.1052 \pm 0.1557$ ) and Caryophyllia (slope: $0.05545 \pm 0.008$; intercept: $0.0302 \pm 0.1116$ ) are indistinguishable in slope and intercept from the inorganic calibration line (slope: $0.0597 \pm 0.004$; intercept: $.03112 \pm$ $0.0475)$. Note, however, that these equations are not suitable for extrapolation beyond the range of observations $\left(0-50{ }^{\circ} \mathrm{C}\right)$.

\subsection{Internal and external standard errors}

The average standard error for our $\Delta_{47}$ measurements are in agreement with the shot noise limit predicted for the analyses (Fig. 2). Samples that were run for several hours have the lowest standard error, on the order of $0.005 \%$, which corresponds to a $1{ }^{\circ} \mathrm{C}$ temperature change for low temperatures on the Ghosh et al. (2006) temperature scale. Several of the corals examined in this study were analyzed multiple times each, permitting us to estimate the external reproducibility for individual measurements of a given sample. This external standard error (i.e., the standard error of the average of multiple extractions) ranges from $0.005 \%$ to $0.014 \%\left(1-2.8^{\circ} \mathrm{C}\right)$, and decreases with the number of measurements (Fig. 3). If one extraction of

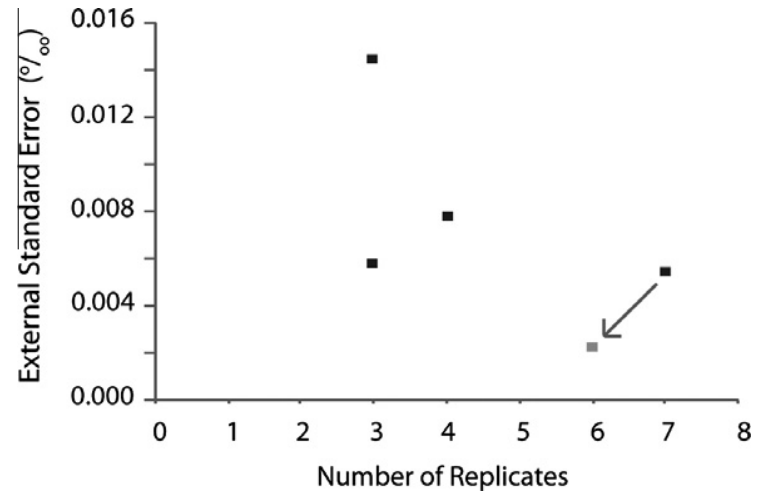

Fig. 3. A figure of the external standard error of our measurements. Multiple replicates decreases the standard error of our measurements. The arrow indicates how coral 47413 changes if one extraction (suspected of having exchanged with water) is removed.

sample 47413 (a measurement which we suspect the extracted $\mathrm{CO}_{2}$ was compromised by exchange of water) is excluded from these statistical calculations, the external standard error ranges from $0.002 \%$ to $0.014 \%(0.4$ $\left.2.8^{\circ} \mathrm{C}\right)$. This external standard error is still larger than the expected shot noise errors for the same samples $(\sim 0.0025-0.0040 \%)$. The difference in external standard error from expected shot noise limits may be due to sample heterogeneity, unaccounted for analytical fractionations, or contaminants in the sample.

The reproducibility we document has implications for future analyses of deep-sea corals. If sample size is limited, the best precision attainable is $0.005 \%\left( \pm 1^{\circ} \mathrm{C}\right)$. However if sample size is not the limiting factor, the coral is homogenous, and not contaminated or otherwise analytically fractionated, precision is demonstrably as good as $0.002 \%$ $\left( \pm 0.4{ }^{\circ} \mathrm{C}\right)$.

\section{DISCUSSION}

\subsection{Relationship of $\Delta_{47}$ to temperature}

For two of the solitary coral genera analyzed in this study, each exhibit slopes and intercepts in a plot of

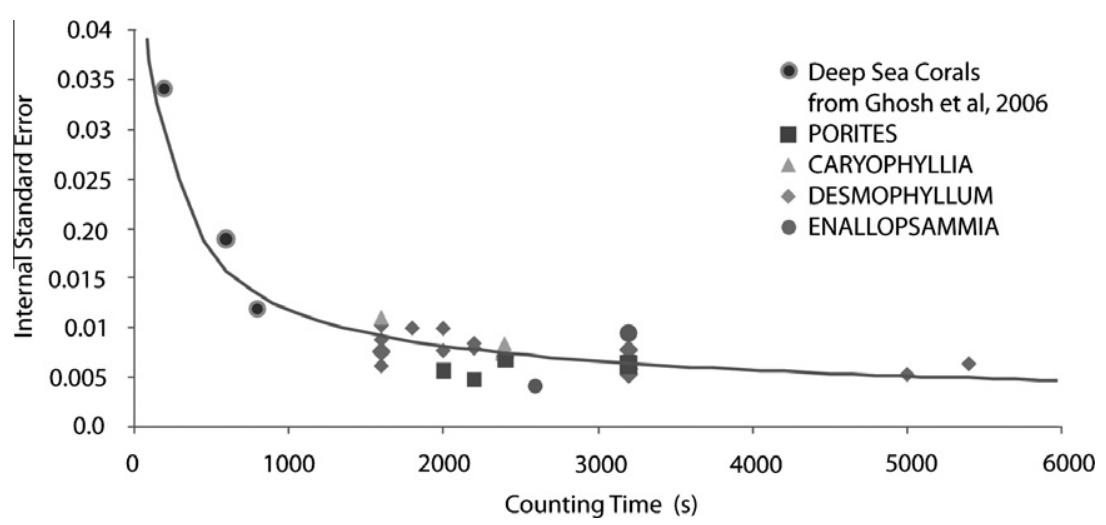

Fig. 2. Internal standard error of our measurements with time. The dark line is the shot noise calculation. The error in our measurements is dominated by shot noise errors and decreases with increasing counting time. 
$\Delta_{47}$ vs. $1 / T^{2}$ that are within error of the inorganic calibration line (Fig. 1). Since the publication of the Ghosh et al. (2006) calibration, several more measurements have been made of inorganic calcite, foraminifera, mollusks, and soil carbonates having independently known growth temperatures. Most of these previous measurements are indistinguishable from the inorganic calibration line (Came et al., 2007; Daeron et al., 2007; Tripati et al., 2010). There have however been non-equilibrium results obtained for speleothems and some synthetic carbonates (Affek et al., 2008; Guo, 2009). And, a recently published calibration for inorganic synthetic calcite (Dennis and Schrag, 2010) disagrees with the Ghosh et al. (2006) result at low temperatures $\left(<\sim 15^{\circ} \mathrm{C}\right)$. The source of this discrepancy is unclear; it could reflect some combination of analytical artifacts (including intralaboratory calibration discrepancies) and/or kinetic isotope effects in carbonate synthesis reactions in either or both studies. We simply note here that this study presents data for 15 samples analyzed in this low temperature range, and they follow a temperaturedependence closely similar to that proposed by Ghosh et al. (2006), but steeper than that presented by Dennis and Schrag (2010). We suggest two straightforward explanations for this result: either the Ghosh et al. (2006) data reflect a kinetic isotope effect at low temperature that is mimicked by a vital effect in deep-sea corals (and, similarly, other classes of organisms previously observed to conform to the Ghosh et al. (2006) trend), yet independent of the vital effect on $\delta^{18} \mathrm{O}$ and $\delta^{13} \mathrm{C}$ in those corals (see below); or the Dennis and Schrag (2010), calibration is influenced by a kinetic isotope effect in low temperature experiments. In the absence of any additional constraints, the second of these seems to us to be the more plausible explanation, and we will presume this for the rest of this discussion. But, we emphasize that inorganic calibrations will likely remain a subject of ongoing research and this interpretation should be revisited as new data come to light.

Three individual analyses made as part of this study are inconsistent with the inorganic calcite calibration trend (i.e., differ from it by more than 2 sigma external error). Two of the outliers are an extraction from each of the samples 47413 and 48738. These outliers were extractions from corals that have been analyzed several times, and in both cases all other extractions from that sample exhibited no offset in $\Delta_{47}$ from the inorganic calibration line. Sample 47413 is unusual because, although the outlier was free of recognized contaminants, it did have a higher $\Delta_{47}$ and lower $\delta^{18} \mathrm{O}$ than all the other replicates of that sample. This combination indicates that it could have exchanged with water (Pasadena tap water: $25{ }^{\circ} \mathrm{C}, \delta^{18} \mathrm{O}=-8 \%$ ) at some point during sample processing. Sample 48738 has an orange organic crust coating it, implying that perhaps it is not modern or that the organic coating was not completely removed prior to sample processing and affected the measurement. In any event, these two measurements are irreproducible exceptions to the otherwise straightforward trend produced by all other analyses, and thus we do not believe they indicate any systematic discrepancy between corals and inorganic calcite in $\Delta_{47}$ systematics. The third outlier is 77019 , an Enallopsammia from $30^{\circ} \mathrm{N}, 76^{\circ} \mathrm{W}$ at $494 \mathrm{~m}$ of water depth in the core of the Gulf Stream, a region known for seasonal and interannual variations in salinity. This coral is also peculiarly enriched in $\delta^{18} \mathrm{O}$ indicating possible uncertainties in the $\delta^{18} \mathrm{O}_{\mathrm{w}}$ reconstructed at this site.

The accuracy of deep-sea coral temperature estimates based on the calibration in Fig. 1 will depend on uncertainties in both the $\Delta_{47}$ of the sample and uncertainties in the calibration line, whereas the precision of sample-to sample differences will depend only on the $\Delta_{47}$ measurements of samples. If one considers all previous measurements of published and unpublished inorganic and biogenic calibration materials (egg shells, teeth, otoliths, mollusks, brachiopods, corals and foraminifera; we exclude here the recent inorganic data of Dennis and Schrag (2010), discussed above) to be part of a single trend (i.e., because trends defined by each material are statistically indistinguishable), then they make up a calibration line of slope in $\Delta_{47}$ vs. $1 / T^{2}$ space of $0.0548 \pm 0.0019$ and intercept of $-0.0303 \pm 0.0221$. The standard error of the calibration is $0.0018 \%$. If one excludes otoliths, which differ most from the other trends (perhaps due to a small vital effect, or due to inaccuracies in estimated body temperatures, or some other factor) and planktic foraminifera (where the variation in temperature with water depth and season is large and therefore means are hard to estimate with confidence), the calibration line has a slope and intercept of $0.0562 \pm 0.0020$ and $0.0167 \pm 0.0226$. The standard error in the calibration is then $0.0019 \%$. The formal errors in slope and intercept of the overall calibration are trivially small; though one should not extrapolate the fitted trend outside of its range in calibration temperatures (particularly at higher temperatures, where the slope flattens considerably; (Eiler et al., 2009; Dennis and Schrag 2010). Thus, barring some unrecognized systematic error in all of the calibration data sets, the accuracy of temperature estimates of samples is dominated by error in the $\Delta_{47}$ measurement of the sample, which is generally dominated by shot noise error. The shot noise error for $\Delta_{47}$ analyses under normal analytical conditions generally levels off (ceases to improve with increased counting time) at $\sim 0.005 \%$ o (or $\sim 1{ }^{\circ} \mathrm{C}$ ) after $4500 \mathrm{~s}$ or $\sim 20$ acquisitions. Current analytical methods require $11 \mathrm{mg}$ of $\mathrm{CaCO}_{3}$ for $4500 \mathrm{~s}$ (i.e., to achieve $0.005 \%$ precision). If large amounts of homogeneous sample are available, precision could be improved further by combining data from multiple measurements of $11 \mathrm{mg}$ sample aliquots. Sub-degree precisions should be possible in this case. For example, if $11 \mathrm{mg}$ of coral analyzed for $4500+$ seconds resulted in a measurement of $2{ }^{\circ} \mathrm{C}$ with a standard error of $0.005 \%$, or $1{ }^{\circ} \mathrm{C}$, then six $11 \mathrm{mg}$ measurements of the same homogeneous coral could result in a precision as low as $0.002 \%$ or $0.4{ }^{\circ} \mathrm{C}$ (plus the small error in the accuracy of the calibration). Or, if three replicate measurements were made for the top of a deep-sea coral and six of the bottom of the same deep-sea coral (i.e., if one were searching for evidence of temperature change over the course of its growth), the error in the temperature estimate at the top would be $\pm 0.4^{\circ} \mathrm{C}$, the error in the temperature at the bottom would be $\pm 0.7^{\circ} \mathrm{C}$, and the temperature difference $(\Delta T=$ top temperature - bottom temperature) would have an error of \pm 0.8 (because the two errors would be added in quadrature). 


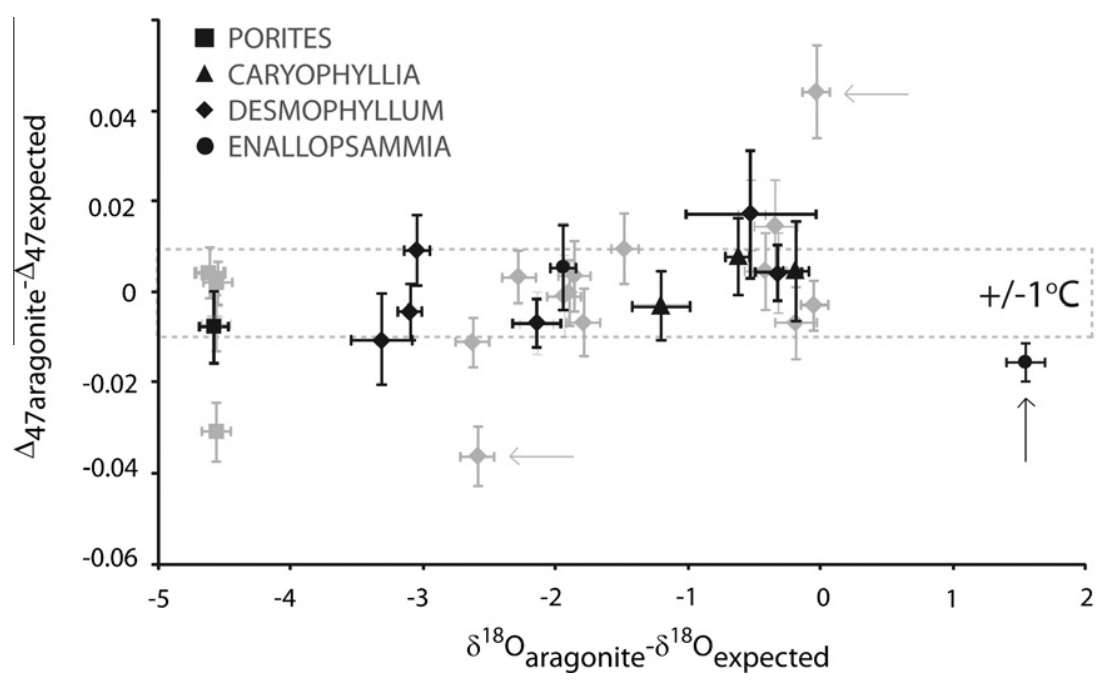

Fig. 4. Offsets from equilibrium in $\Delta_{47}$ and $\delta^{18} \mathrm{O}$. The biggest offsets in $\Delta_{47}$ are from corals with multiple extractions and every other extraction from those corals have no offset in $\Delta_{47}$. The averages of replicates of the same coral (individual measurements of those corals are shown with the faded symbols) are shown with external standard errors. The measurements with arrows (are the ones indicated in Fig. 1) and are outliers discussed in the text.

\subsection{Vital effects mechanisms}

\subsubsection{Vital effects in corals}

Use of deep-sea corals (and other biogenic carbonates) as a paleoceanographic archive is complicated by a set of biological processes commonly referred to as vital effects. Vital effects have been observed in aragonitic corals as offsets from equilibrium in stable isotope and metal/calcium ratios for a given temperature and other equilibrium conditions. Vital effects in corals and other organisms have also been noted to be dependent on growth rate, kinetics, $\mathrm{pH}$, light, and to the presence or absences of photosymbionts (Weber and Woodhead, 1970; McConnaughey, 1989; Cohen et al., 2002; Rollion-Bard et al., 2003; Reynaud et al., 2007).

The range of vital effects in conventional, or 'bulk' stable isotope compositions seen in deep-sea corals is $7 \%$ in $\delta^{18} \mathrm{O}$ and $12 \%$ in $\delta^{13} \mathrm{C}$. In contrast, $\Delta_{47}$ values do not appear to exhibit any vital effects (i.e., they remain indistinguishable from the inorganic calibration across the full studied temperature range). The analytical method used to determine $\Delta_{47}$ values simultaneously generates $\delta^{13} \mathrm{C}$ and $\delta^{18} \mathrm{O}$ values for the sample; therefore, it is possible for us to evaluate the extent to which each analyzed sample expressed 'vital effects' in their $\mathrm{O}$ and $\mathrm{C}$ isotope compositions. A plot of $\Delta_{47 \text { measured }}-\Delta_{47 \text { expected }}$ vs. $\delta^{18} \mathrm{O}_{\text {measured }}-\delta^{18} \mathrm{O}_{\text {expected }}$ does not show any correlated trends, and there are no systematic deviations in $\Delta_{47 \text { measured }}$ from $\Delta_{47 \text { expected }}$ even when there are clearly offsets in $\delta^{18} \mathrm{O}$ (Fig. 4). While our study was not designed to examine the mechanisms of vital effects, our results offer new constraints on this problem.

The following sections compare our results with the predictions one would make based on various previouslyproposed vital effect mechanisms.

\subsubsection{Diffusion}

Diffusion of $\mathrm{CO}_{2}$ through a lipid bilayer or of different carbonate species across a foraminifer shell has been proposed as a part of different vital effect models (Zeebe et al., 1999; Adkins et al., 2003; Erez, 2003). While we do not have a first principle understanding of how this type of diffusion might affect the $\Delta_{47}$ value, we can use other types of well-known diffusion to inform this discussion. The kinetic theory of gases predicts that a gas that is diffused through a small aperture ('Knudsen diffusion') will be depleted in heavy isotopes relative to the residual gas it leaves behind. This behavior is described by the equation $R_{\text {diffused }}^{j}=R_{\text {residue }}^{j}\left(M_{i} / M_{j}\right)^{0.5}$ where $R_{j}$ is the ratio of the concentration of isotopologue $j$ to $i$ and $M$ is the mass.

Knudsen diffusion predicts that for a $\mathrm{CO}_{2}$ population that has undergone diffusive fractionation, the diffused gas will be $11.2 \%$ lower in $\delta^{13} \mathrm{C}$, and $22.2 \%$ lower in $\delta^{18} \mathrm{O}$, but only $0.5 \%$ higher in $\Delta_{47}$. This seemingly counterintuitive behavior is due to the non-linear dependence of the stochastic abundances of mass- $47 \mathrm{CO}_{2}$ isotopologues on the bulk isotopic composition (Eiler and Schauble, 2004). For natural isotopic compositions, the stochastic abundance increases more for an incremental change in $\delta^{13} \mathrm{C}$ or $\delta^{18} \mathrm{O}$ than does the vector that describes diffusive fractionation in $\delta^{13} \mathrm{C}, \delta^{18} \mathrm{O}$ and $\Delta_{47}$ space. Therefore, a diffused population of gas would be more depleted in $\delta^{13} \mathrm{C}$ and $\delta^{18} \mathrm{O}$ but higher than expected in $\Delta_{47}$.

Similarly, gas phase inter-diffusion where gas A diffuses through gas $\mathrm{B}$ is described by the relation $D_{a} / D_{a^{\prime}}=$ $\left\{\left(M_{a}+M_{b}\right) /\left(M_{a} M_{b}\right) \times\left(M_{a}^{\prime} M_{b}\right) /\left(M_{a}^{\prime}+M_{b}\right)^{0.5}\right\}$, where $M_{a}$ is the mass of the diffusing molecule, $M_{b}$ is the mass of the gas through which gas $\mathrm{A}$ is diffusing and the primes indicate the presence of a heavy isotope. The gas phase diffusion of $\mathrm{CO}_{2}$ through air generates fractionations of $-4.4 \%$ for $\delta^{13} \mathrm{C},-8.7 \%$ for $\delta^{18} \mathrm{O}$ and $+0.3 \%$ for $\Delta_{47}$. The enrichment of $\Delta_{47}$ in the diffused phase is again due to the relatively strong dependence of the stochastic abundance of mass $-47 \mathrm{CO}_{2}$ on the bulk isotopic composition.

Isotopic fractionations caused by diffusion of molecules through a liquid medium are generally smaller than those 


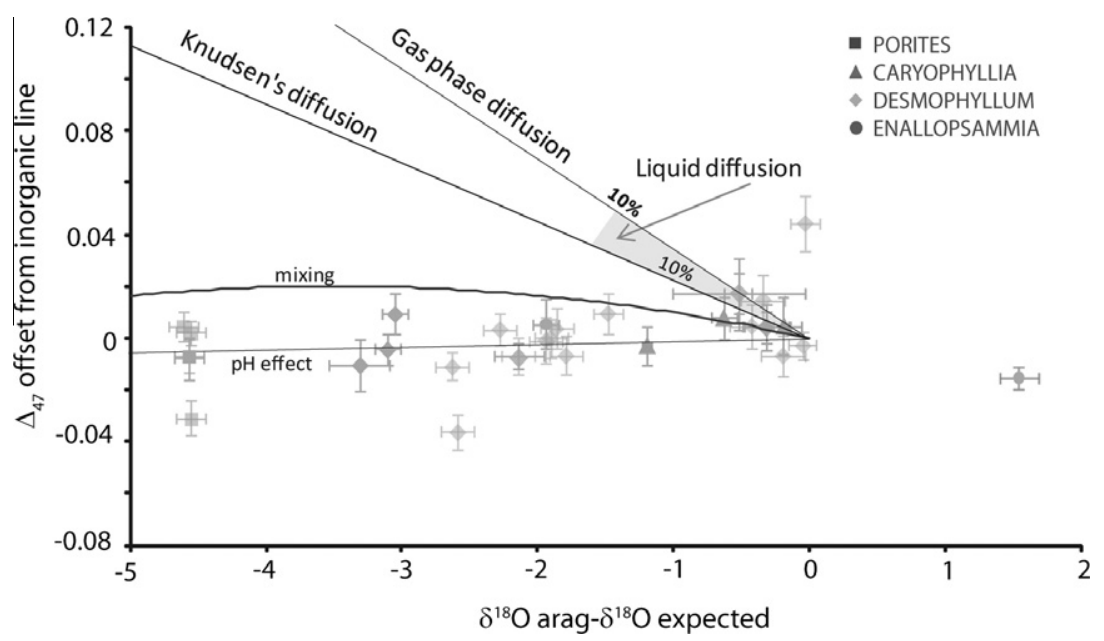

Fig. 5. Vectors describing how various processes effect $\Delta_{47}$ and $\delta^{18} \mathrm{O}$. Diffusive and mixing processes cannot explain the coupled variation seen in $\Delta_{47}$ and $\delta^{18} \mathrm{O}$; however $\mathrm{pH}$ effects can.

associated with gas-phase diffusion. For instance the ratio of diffusion coefficients of ${ }^{12} \mathrm{CO}_{2}$ and ${ }^{13} \mathrm{CO}_{2}$ in water is 1.0007 (O'Leary, 1984), whereas the gas phase interdiffusion equation, taking the medium to be $\mathrm{H}_{2} \mathrm{O}$ predicts a fractionation factor of 1.0032. However, these condensed phase diffusive fractionations are generally described through a power-law relationship (i.e., the fractionation factor scales as the ratio of masses to some power, generally less than 0.5) (Bourg and Sposito, 2008). In this case, the mass dependence of the diffusive fractionation remains the same as for Knudsen diffusion, and the slope followed in a plot of $\Delta_{47}$ vs. $\delta^{18} \mathrm{O}$ or $\delta^{13} \mathrm{C}$ will remain the same. If so, then liquid phase diffusion of $\mathrm{CO}_{2}$ should result in fractionations of $-0.7 \%$ for $\delta^{13} \mathrm{C}$ (i.e., the experimental constraint), $-1.6 \%$ for $\delta^{18} \mathrm{O}$ and $+0.036 \%$ for $\Delta_{47}$. On Fig. 5 we have also indicated what $10 \%$ of the Knudsen and gas phase interdiffusion vector are to emphasize the difference between the scale of the different vectors.

If deep-sea coral growth involved non-equilibrium isotopic fractionations that were dominated by diffusion across a lipid bilayer or in an aqueous medium, then a plot of $\Delta_{47} \mathrm{vs}$. $\delta^{18} \mathrm{O}$ might have the same slope as the vectors that describe the types of diffusion discussed above. However the data is inconsistent with any of these predicted slopes (Fig. 5). In addition, all of the diffusive processes predict $\delta^{13} \mathrm{C}$ variations smaller than $\delta^{18} \mathrm{O}$ variations, which is opposite to what is seen in deep-sea corals.

\subsubsection{Mixing}

The stochastic distribution that defines the reference frame for reporting $\Delta_{47}$ values has a subtle saddle-shape curvature in a 3 -dimensional plot of $\delta^{13} \mathrm{C}$ vs., $\delta^{18} \mathrm{O}$ vs. $\mathrm{R}^{47}$. Therefore, conservative mixing of two $\mathrm{CO}_{2}$ populations with the same $\Delta_{47}$ but different $\delta^{13} \mathrm{C}$ and $\delta^{18} \mathrm{O}$ leads to a mixed population having a different $\Delta_{47}$ value than the weighted sum of the $\Delta_{47}$ values of the end members (Eiler and Schauble, 2004).

Deep-sea corals have a large variation in $\delta^{13} \mathrm{C}$ and $\delta^{18} \mathrm{O}$ and could possibly produce $\Delta_{47}$ signals solely from this mixing effect. The range of variations seen in a single coral can be as large as $12 \%$ in $\delta^{13} \mathrm{C}$ and $7 \%$ in $\delta^{18} \mathrm{O}$ (Adkins et al., 2003). Two example endmembers seen in $\delta^{13} \mathrm{C}$ and $\delta^{18} \mathrm{O}$ are $\delta^{13} \mathrm{C}=-10 \%$ and $\delta^{18} \mathrm{O}=-2 \%$, and $\delta^{13} \mathrm{C}=2 \%$ and $\delta^{18} \mathrm{O}=5 \%$. If the stable isotopic variation in a deepsea coral reflects variation in the DIC pool that the coral was using for calcification, we can calculate what magnitude of $\Delta_{47}$ offset would result from mixing between the isotopic end members of the DIC pool. However, the carbonate species of interest for calcification is not $\mathrm{CO}_{2}$ (and its $\Delta_{47}$ value) but $\mathrm{CO}_{3}$ and its corresponding ${ }^{13} \mathrm{C}-{ }^{18} \mathrm{O}$ clumped isotopologue. The relevant isotope exchange reaction for $\mathrm{CO}_{3}$ species is:

$$
{ }^{12} \mathrm{C}^{18} \mathrm{O}^{16} \mathrm{O}_{2}^{2-}+{ }^{13} \mathrm{C}^{16} \mathrm{O}_{3}^{2-} \Longleftrightarrow{ }^{13} \mathrm{C}^{18} \mathrm{O}^{16} \mathrm{O}_{2}^{2-}+{ }^{12} \mathrm{C}^{16} \mathrm{O}_{3}^{2-}
$$

So, we calculated the mixing effect on $\Delta_{63}$ (i.e., enrichment in mass-63 carbonate ion isotopologues, analogous to the $\Delta_{47}$ values of $\mathrm{CO}_{2}$ ) and then converted this to a $\Delta_{47}$ value that would be measured in a coral skeleton. If both the high- and low- $\delta^{13} \mathrm{C}$ and $\delta^{18} \mathrm{O}$ share a common " $\Delta_{63}$ " value then we predict the amplitude of this mixing effect is as large as $0.02 \%$ for the case of $50 \%$ of each end member (which would generate the largest $\Delta_{63}$ offset, and still a relatively large offset in $\delta^{18} \mathrm{O}$ ). Because phosphoric acid is believed to produce $\mathrm{CO}_{2}$ having a $\Delta_{47}$ value that is offset by a constant amount from the $\Delta_{63}$ value of reactant carbonate (for a fixed temperature of reaction) this $0.02 \%$ enrichment due to mixing should be directly inherited by analyzed $\mathrm{CO}_{2}$ (Guo et al., 2009). It is clear that this mixing model is inconsistent with the data, as there is no curvature to the $\Delta_{47}$ vs. $\delta^{18} \mathrm{O}$ trend unlike the mixing model (Fig. 5). However, it is possible that mixing accompanied by re-equilibration would generate a horizontal line, and thus be more consistent with the data. Further experiments are needed to determine the rate that carbonate precipitating from DIC incorporates the different clumped carbonate species in DIC and whether mixing and subsequent reequilibration would be recorded in the precipitating carbonates. 


\subsection{4. $p H$}

It has been demonstrated for inorganically precipitated carbonates that higher $\mathrm{pH}$ values (and thus higher $\mathrm{CO}_{3}^{2-}$ proportions in DIC) result in isotopically lower $\delta^{18} \mathrm{O}$ values (McCrea, 1950; Usdowski et al., 1991). This observation has been explained by the $\mathrm{pH}$ dependent speciation of the DIC pool from which carbonate precipitates and the different fractionation factors between water and these DIC species. At seawater like $\mathrm{pHs} \mathrm{HCO}_{3}^{-}$dominates and at high pHs $\mathrm{CO}_{3}^{2-}$ dominates the DIC. McCrea (1950) and Usdowski et al. (1991) demonstrated that if calcium carbonate is quantitatively precipitated from a bicarbonatecarbonate solution, the oxygen isotopic composition of the solid reflects the weighted average of all the fractionation factors with respect to water for all the carbonate species. Zeebe (1999) exploited this observation to explain the variation seen in the inorganic carbonate data in Kim and O'Neil (1997) and existing stable oxygen isotope ratios of foraminiferal calcite.

It would be helpful to understand how the clumped isotope composition of the DIC varied with $\mathrm{pH}$. Guo et al. (2008) theoretically estimated the $\Delta_{63}$ values of dissolved carbonate species in water; at $300 \mathrm{~K}, \mathrm{CO}_{3}^{2-}$ has a predicted value of $0.403 \%$, whereas $\mathrm{HCO}_{3}^{-}$has a value of $0.421 \%$. While the absolute values of these calculated $\Delta_{63}$ estimates vary with the parameterization of the computational model, the offset between $\mathrm{CO}_{3}^{2}$ and $\mathrm{HCO}_{3}^{-}$remains constant at $\sim 0.018 \%$, and thus could be a robust feature of the calculation (Guo et al., 2008). The equivalent difference in $\delta^{18} \mathrm{O}$ with respect to water at $19{ }^{\circ} \mathrm{C}$ is $34.3 \%$ for $\mathrm{HCO}_{3}^{-}$and $18.4 \%$ for $\mathrm{CO}_{3}^{2-}$ (Zeebe, 1999).

Given Zeebe's model of precipitation and Guo et al's. (2008) calculated differences in $\Delta_{63}$ between $\mathrm{HCO}_{3}^{-}$and $\mathrm{CO}_{3}^{2-}$, we estimate the $\mathrm{pH}$ dependence of $\Delta_{63}$ of carbonate (which we take to be proportional to the measured $\Delta_{47}$ of $\mathrm{CO}_{2}$ extracted from those carbonates). A change in $\mathrm{pH}$ from 7.9 to 9.8 leads to a change in $\mathrm{CO}_{3}^{2-}$ as a proportion of all DIC from $5 \%$ to $75 \%$ and a predicted change in $\Delta_{63}$ of carbonates by $0.0126 \%$ and in $\delta^{18} \mathrm{O}$ of carbonates by $10.92 \%$. Thus, Zeebe's model predicts a slope of $\Delta_{47}$ vs. $\delta^{18} \mathrm{O}$ measured in carbonate that closely approaches 0 . However since the absolute values of the $\Delta_{63}$ estimates of the DIC species (and their relative difference to the calcium carbonate is unknown) the $\mathrm{pH}$ vector can only be plotted on Fig. 5 with certain assumptions. Here we assume that when there is no offset in $\delta^{18} \mathrm{O}$ from equilibrium, similarly there is no offset in $\Delta_{47}$ from the inorganic calibration line. That is, we are examining the sensitivity to $\mathrm{pH}$ not the absolute values of the $\Delta_{63}$ of the DIC species implied by different computational models. The resulting $\mathrm{pH}$ vector is consistent with our results (Fig. 5).

\subsubsection{Other vital effect models}

Watson (2004) proposed a model for near-surface kinetic controls on stable isotope compositions in calcite crystals, which also involves sensitivity to DIC speciation. The model is based on the idea that the concentration of a particular trace-element in a crystal (which we could take to be an isotopologue of carbonate ion for our purposes) is primarily determined by two factors: the concentration of the element in the near-surface region of the crystal and the competition between crystal growth and ion migration in the near-surface region. There are three key regions, the specific growth surface which is a monolayer of atoms, the near surface region and the bulk crystal lattice. The growth surface of the crystal could (due to its distinct structure) have an equilibrium composition that is different from that of the crystal lattice. Thus if the trace element is selectively enriched (or depleted) on the growth surface, and if the diffusivity of that element in the near-surface region of the crystal is low, then the anomalous surface composition may be partially or completely preserved within the growth sector formed behind the growth surface. If however the diffusivity of the element in the near-surface region of the crystal is high, the newly formed crystal lattice is in equilibrium with the fluid it is growing from and has a different composition than the growth surface. Watson has explored this growth entrapment effect in various trace elements (Okorokov et al., 1996) and also extended it to oxygen isotopes (Watson, 2004).

The Watson model identifies two potential sources of ${ }^{18} \mathrm{O}$ for calcite, $\mathrm{CO}_{3}^{2-}$ species alone or the weighted average of carbonate and bicarbonate ion (i.e., as in Zeebe's model). Carbonate ion is lower in $\delta^{18} \mathrm{O}$ than solid carbonate when equilibrated with a common water. So, the Watson model predicts that if carbonate ion alone is added to growing solid carbonate, the solid will be lower than equilibrium for fast growth and approach equilibrium for slow growth. If instead both bicarbonate and carbonate ion contribute to solid, faster growth rates will be associated with higherthan equilibrium $\delta^{18} \mathrm{O}$ values in the solid (because the higher $\delta^{18} \mathrm{O}$ value of bicarbonate will be 'trapped' in the solid structure). It has been suggested that the $\delta^{18} \mathrm{O}$ of aragonite decreases with increased growth rate in deep sea corals, based on textural variations of $\delta^{18} \mathrm{O}$ within individual corals (Adkins et al., 2003). This observation is consistent with the Watson model for the case that carbonate ion alone contributes to the solid.

Clumped isotopes cannot yet be applied to the Watson model because there are several unknown factors. The $\Delta_{63}$ offset between $\mathrm{CO}_{3}^{2-}$ (aq) and $\mathrm{CO}_{3}^{2-}$ (s) is poorly known. The equilibrium partitioning in clumped isotopes between the fluid and the growth surface and the equilibrium partitioning between the fluid and the bulk crystal lattice is also unknown. The $\Delta_{63}$ of the $\mathrm{CO}_{3}^{2-}$ in aragonite is $0.430 \%$ (Schauble et al., 2006) while the $\Delta_{63}$ of $\mathrm{HCO}_{3}^{-}$and $\mathrm{CO}_{3}^{2-}$ in DIC has been predicted to be $0.421 \%$ and $0.403 \%$, respectively (Guo, 2009); however, because the $\Delta_{63}$ offset between $\mathrm{CO}_{3}$ in water and $\mathrm{CO}_{3}$ in aragonite is sensitive to the solvent model used to calculate the fractionation factors of the dissolved species (see above $\mathrm{pH}$ discussion), Guo's calculations of $\Delta_{63}$ cannot confidently be used to evaluate Watson, 2004) surface entrapment model. If however all these factors were known, then clumped isotopes could be a test for the Watson model.

McConnaughey (1989) used the difference between symbiont bearing and non-symbiont bearing aragonitic coral species from the same growth environment to constrain the chemical mechanisms behind vital effects. He determined that there is a kinetic effect and a metabolic effect 
fractionating oxygen and carbon isotopes in corals. The kinetic effect is due to the kinetic isotope effects (KIE) that occur during $\mathrm{CO}_{2}$ hydration and hydroxylation. Therefore the linear variations seen in $\delta^{13} \mathrm{C}$ and $\delta^{18} \mathrm{O}$ are due to the incomplete isotopic equilibration of $\mathrm{CaCO}_{3}$ and $\mathrm{H}_{2} \mathrm{O}$. Clumped isotopes cannot be used yet to evaluate McConaughey's kinetic fractionation model of stable isotope vital effects in corals as the KIE of $\mathrm{CO}_{2}$ hydration and hydroxylation on clumped isotopes is currently unknown. However, if isotopic disequilibrium due to $\mathrm{CO}_{2}$ hydration and hydroxylation is the dominant control of vital effects in corals then the magnitude of $\Delta_{47} / \delta^{18} \mathrm{O}$ from this effect is constrained to be less than the observed variation in Fig. 5.

Rayleigh fractionation has also been proposed as a possible vital effects mechanism for the distribution of metals in corals (Cohen et al., 2006; Gagnon et al., 2007; Holcomb et al., 2009). This model assumes that there is an initial solution that is close to seawater composition which then undergoes closed system precipitation. Again clumped isotopes cannot yet be used to evaluate this vital effect mechanism as the partition coefficient of $\Delta_{47}$ for inorganic aragonite (where the partition coefficient is defined as: $D^{\text {arag }}$ $\left.\Delta_{47}=\left(\Delta_{47}\right)_{\text {aragonite }} /\left(\Delta_{47}\right)_{\text {seawater }}\right)$ is unknown. The relevant $F$, or extent of precipitation, is also unknown.

\section{CONCLUSIONS}

We present the relationship between the abundance of clumped isotopologues in $\mathrm{CO}_{2}$ produced by phosphoric digestion of deep-sea corals and the coral to growth temperature. Deep-sea corals exhibit a temperature-dependent trend in $\Delta_{47}$ value that is indistinguishable in slope and intercept from inorganic calcite. This result indicates that deep sea corals can be used for paleothermometry, with precisions as good as $\sim 0.5^{\circ} \mathrm{C}$. We also observe no vital effects in $\Delta_{47}$ for samples that display large vital effects in $\delta^{18} \mathrm{O}$. This result is inconsistent with the predicted effects of diffusion or mixing for vital effects. However, $\mathrm{pH}$ effects could explain the observed variations in $\Delta_{47}$ and $\delta^{18} \mathrm{O}$. In contrast to the results for Red Sea corals presented in Ghosh et al. (2006), we find no evidence of vital effects in surface corals. One of several possible explanations for this difference is that we analyzed mean annual bands in the surface coral rather than specific seasons (i.e., perhaps vital effects are specific only to relatively thin winter-growth bands in surface corals). Future work would involve a more detailed analysis of surface corals within annual bands to confirm the existence and determine the nature of any vital effect.

The degree-level errors in temperature in clumped isotope thermometry indicate that it is most suitable for thermocline and sea surface temperature studies, where temperature ranges are of-order $10^{\circ} \mathrm{C}$. However, subdegree precision is possible by averaging multiple replicates of homogeneous samples, making deep sea ocean temperatures studies (where temperature ranges are typically a few degrees) feasible.

Previous estimates of deep-sea temperature change across glacial/interglacial cycles have been made, using a combination of $\mathrm{Mg} / \mathrm{Ca}$ ratios, or $\delta^{18} \mathrm{O}_{\mathrm{w}}$ with sea level curves. It is thought that in the deep Pacific the temperature changed $2{ }^{\circ} \mathrm{C}$, and the Atlantic changed by $4{ }^{\circ} \mathrm{C}$, between MIS 5c and by $2{ }^{\circ} \mathrm{C}$ (Cutler et al., 2003). Given the appropriate samples and sufficient effort at analytical replication, the clumped isotope thermometer should be able to further constrain glacial/interglacial temperature changes in the deep ocean.

\section{ACKNOWLEDGEMENTS}

We would like to thank Weifu Guo and Alexander Gagnon for helpful conversations. We would also like to thank Rinat Gabitov and two anonymous reviewers for their comments. We also thank The National Museum of Natural History for lending us deep-sea coral samples.

\section{REFERENCES}

Adkins J. F., Boyle E. A., Curry W. B. and Lutringer A. (2003) Stable isotopes in deep-sea corals and a new mechanism for "vital effects". Geochimica et Cosmochimica Acta 67, 1129-1143.

Adkins J. F., Griffin S., Kashgarian M., Cheng H., Druffel E. R. M., Boyle E. A., Edwards R. L. and Shen C.-C. (2002b) Radiocarbon dating of deep-sea corals. Radiocarbon 44, 567-580.

Adkins J. F., McIntyre K. and Schrag D. P. (2002a) The salinity, temperature, and ${ }^{18} \mathrm{O}$ of the glacial deep ocean. Science $\mathbf{2 9 8}$, $1769-1773$.

Affek H. P., Bar-Matthews M., Ayalon A., Matthews A. and Eiler J. M. (2008) Glacial/interglacial temperature variations in Soreq cave speleothems as recorded by [']clumped isotope' thermometry. Geochimica et Cosmochimica Acta 72, 5351-5360.

Blunier T. and Brook E. (2001) Timing of millennial-scale climate change in Antarctica and Greenland during the last glacial period. Science 291, 109-112.

Bourg I. C. and Sposito G. (2008) Isotopic fractionation of noble gases by diffusion in liquid water: molecular dynamics simulations and hydrologic applications. Geochimica et Cosmochimica Acta 72, 2237-2247.

Came R. E., Eiler J. M., Veizer J., Azmy K., Brand U. and Weidman C. R. (2007) Coupling of surface temperatures and atmospheric $\mathrm{CO}_{2}$ concentrations during the Palaeozoic era. Nature 449, 198-201.

Chappell J. and Shackleton N. J. (1986) Oxygen isotopes and sea level. Nature 324, 137-140.

Cohen A., Owens K. E., Layne G. and Shimizu N. (2002) The effect of algal symbionts on the accuracy of $\mathrm{Sr} / \mathrm{Ca}$ paleotemperatures from coral. Science 296, 331-333.

Cohen A. L., Gaetani G. A., Lundalv T., Corliss B. H. and George R. Y. (2006) Compositional variability in a cold-water scleractinian, Lophelia pertusa: new insights into "vital effects". Geochemistry Geophysics Geosystems 7. doi:10.1029/ 2006GC001354.

Cutler K. B., Edwards R. L., Taylor F. W., Cheng H., Adkins J., Gallup C. D., Cutler P. M., Burr G. S., Chappell J. and Bloom A. L. (2003) Rapid sea-level fall and deep-ocean temperature change since the last interglacial. Earth and Planetary Science Letters 206, 253-271.

Daeron M., Quade J., Eiler J. 2007. Clumped-isotope thermometry of modern pedogenic carbonates. Agu Fall Meeting Abstracts.

Dennis K. J. and Schrag D. P. (2010) Clumped isotope thermometry of carbonatites as an indicator of diagenetic alteration. Geochimica et Cosmochimica Acta 74, 4110-4122.

Eiler J. A., Schauble E. and Kitchen N. (2003) (Coo)-C-13-O-18-O16 in air. Geochimica et Cosmochimica Acta 67, A86. 
Eiler J. M. and Schauble E. (2004) ${ }^{18} \mathrm{O}^{13} \mathrm{C}^{16} \mathrm{O}$ in earth's atmosphere. Geochimica et Cosmochimca Acta 68, 4767-4777.

Eiler, J., Bonifacie, M., and Daeron, M, 2009. 'Clumped Isotope' Thermometry for High-Temperature Problems. Geochimica et Cosmochimica Acta Conference Abstracts, A322.

Emiliani C. (1955) Pleistocene temperatures. Journal of Geology 63, 538-578.

Emiliani C., Hudson J. H., Shinn E. and George R. Y. (1978) Oxygen and carbon isotopic growth record in a reef coral from the Florida Keys and a deep-sea coral from Blake Plateau. Science 202, 627-629.

Epstein S., Buchsbaum R., Lowenstam H. A. and Urey H. C. (1953) Revised carbonate-water isotopic temperature scale. Geological Society of America Bulletin 64, 1315-1326.

Erez J. (2003) The sources of ions for biomineralization in foraminifera and their implications for paleoceanographic proxies. In Reviews in Mineralogy and Geochemistry: Biomineralization (eds. Patricia M. Dove, Steve Weiner and James J. De Yoreo). Mineralogical Society of America, Washington, DC.

Gagnon A. C., Adkins J. F., Fernandez D. P. and Robinson L. F. (2007) $\mathrm{Sr} / \mathrm{Ca}$ and $\mathrm{Mg} / \mathrm{Ca}$ vital effects correlated with skeletal architecture in a scleractinian deep-sea coral and the role of Rayleigh fractionation. Earth and Planetary Science Letters 261, 280-295.

Ghosh P., Adkins J. F., Affek H., Balta B., Guo W., Schauble E. A., Schrag D. P. and Eiler J. M. (2006) ${ }^{13} \mathrm{C}-{ }^{18} \mathrm{O}$ bonds in carbonate minerals: a new kind of paleothermometer. Geochimica et Cosmochimica Acta 70, 1439-1456.

Guo, W., 2009. Carbonate clumped isotope thermometry: application to carbonaceous chondrites and effects of kinetic isotope fractionation, California Institute of Technology.

Guo W., Daeron M., Niles P., Genty D., Kim S. T., Vonhof H., Affek H., Wainer K., Blamart D. and Eiler J. (2008) C-13-O-18 bonds in dissolved inorganic carbon: Implications for carbonate clumped isotope thermometry. Geochimica et Cosmochimica Acta 72, A336.

Guo W., Mosenfelder J. L., Goddard Iii W. A. and Eiler J. M. (2009) Isotopic fractionations associated with phosphoric acid digestion of carbonate minerals: insights from first-principles theoretical modeling and clumped isotope measurements. Geochimica et Cosmochimica Acta 73, 7203-7225.

Holcomb M., Cohen A. L., Gabitov R. I. and Hutter J. L. (2009) Compositional and morphological features of aragonite precipitated experimentally from seawater and biogenically by corals. Geochimica et Cosmochimica Acta 73, 4166-4179.

Kim S.-T. and O’Neil J. R. (1997) Equilibrium and non-equilibrium oxygen isotope effects in synthetic carbonates. Geochimica et Cosmochimica Acta 61, 3461-3475.

McConnaughey T. (1989) ${ }^{13} \mathrm{C}$ and ${ }^{18} \mathrm{O}$ isotopic disequilibrium in biological carbonates: I. patterns. Geochimica et Cosmochimica Acta 53, 151-162.

McCrea J. M. (1950) On the isotopic chemistry of carbonates and a paleotemperature scale. Journal of Chemical Physics 18, 849857.
O'Leary M. H. (1984) Measurement of the isotope fractionation associated with diffusion of carbon dioxide in aqueous solution. The Journal of Physical Chemistry 88, 823-825.

Okorokov A. L., Panov K. I., Kolbanovskaya E. Y., Karpeisky M. Y., Polyakov K. M., Wilkinson A. J., Dodson G. G. and Watson E. B. (1996) Surface enrichment and trace-element uptake during crystal growth. Geochimica et Cosmochimica Acta 60, 5013-5020.

Reynaud S., Ferrier-Pagès C., Meibom A., Mostefaoui S., Mortlock R., Fairbanks R. and Allemand D. (2007) Light and temperature effects on $\mathrm{Sr} / \mathrm{Ca}$ and $\mathrm{Mg} / \mathrm{Ca}$ ratios in the scleractinian coral Acropora spp.. Geochimica et Cosmochimica Acta 71, 354-362.

Rollion-Bard C., Chaussidon M. and France-Lanord C. (2003) PH control on oxygen isotopic composition of symbiotic corals. Earth and Planetary Science Letters 215, 275-288.

Schauble E. A., Ghosh P. and Eiler J. M. (2006) Preferential formation of ${ }^{13} \mathrm{C}^{-18} \mathrm{O}$ bonds in carbonate minerals, estimated using first-principles lattice dynamics. Geochimica et Cosmochimica Acta 70, 2510-2529.

Schrag D. P. and DePaolo D. J. (1993) Determination of del ${ }^{18} \mathrm{O}$ of seawater in the deep ocean during the Last Glacial Maximum. Paleoceanography 8, 1-6.

Shackleton N. J. (1967) Oxygen isotope analyses and Pleistocene temperatures re-assessed. Nature 215, 15-17.

Tripati A. K., Eagle R. A., Thiagarajan N., Gagnon A. C., Bauch H., Halloran P. R. and Eiler J. M. $(2010){ }^{13} \mathrm{C}^{-18} \mathrm{O}$ isotope signatures and 'clumped isotope' thermometry in foraminifera and coccoliths. Geochimica et Cosmochimca Acta 74, 56975717.

Urey H. C. (1947) The thermodynamic properties of isotopic substances. Journal of the Chemical Society 1947, 562-581.

Usdowski E., Michaelis J., Bottcher M. E. and Hoefs J. (1991) Factors for the oxygen isotope equilibrium fractionation between aqueous and gaseous $\mathrm{CO}_{2}$, carbonic acid, bicarbonate, carbonate, and water $\left(19^{\circ} \mathrm{C}\right)$. Zeitschrift fur Physikalische Chemie 170, 237-249.

Watson E. B. (2004) A conceptual model for near-surface kinetic controls on the trace-element and stable isotope composition of abiogenic calcite crystals. Geochimica et Cosmochimca Acta 68, $1473-1488$.

Weber J. N. and Woodhead P. M. J. (1970) Carbon and oxygen isotope fractionation in the skeletal carbonate of reef-building corals. Chemical Geology 6, 93-117.

Weber J. N. (1973) Deep-sea ahermatypic scleratinian corals: isotopic composition of the skeleton. Deep-Sea Research 20, 901-909.

Zeebe R. (1999) An explanation of the effect of seawater carbonate concentration on foraminiferal oxygen isotopes. Geochimica et Cosmochimica Acta 63, 2001-2007.

Zeebe R. E., Bijma J. and Wolf-Gladrow D. A. (1999) A diffusionreaction model of carbon isotope fractionation in foraminifera. Marine Chemistry 64, 199-227. 